\title{
石本·飯田の統計式における最大振幅指数について
}

\author{
京都大学地球物理学教室 神 村 三 郎 \\ (昭和 29 年 4 月 8 日受理)
}

\section{On the Maximum Amplitude Index in the Ishimoto-Iida's Statistical Formula.}

\author{
By Saburō Kōmura \\ Geophysical Institute, Kyoto University.
}

(Received April 8, 1954)

'The Ishimoto-Iida's statistical formula is represented as follows:

$$
N A^{m}=k,
$$

where, $A$ is a traced maximum amplitude, $N$ is an annual average frequency of small shocks with $A$, and $m$ or $k$ is a constant at that place. The index $m$ shows some different values in accordance with the class number classifying the maximum amplitude.

In applying the Sturges' Formula to its classification, as the result of testing these values by the stochastical method, we have reached the conclusions that we need not consider both values in two directions of horizontal vibration, and moreover, the geophysical meaning of $m$ is not lost, for the value $m=1.9$ in population is not rejected at the significance level of $5 \%$ or $1 \%$.

In recognition of this fact, we shall be able to propose the classifying method based on the Sturges' Formula, i. e.

$$
n=1+\log N / \log 2,
$$

where, $N$ is the total number of data, and $n$ is the suitable class number.

Let us now apply the above method to the observational data obtained at Abuyama during 1949-1953. Thus we shall gain the results that the homogeneity of the $m$ value and $m=1.9$ in population are not rejected $(1 \%)$, regardless of the magnitude, or the extent of the observed domain, or the term of each year of observed earthquakes.

\section{§1. 前}

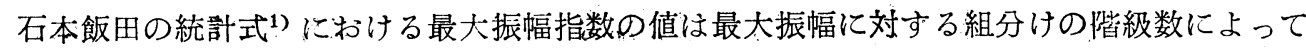
可なり相違する. 又この值は地震動の観測方向別, 使用した地震動の規模の大小, 観測領域の 広狭，等によっても相違している．筆者は此等の諸点に就いて別府地方の微弱小地震群の凟料 と，1949 年から 1953 年に亘る阿武山地震観測の資料に基いて計算を進め，得られた結果に対 し推計学的な立場から；それらの相違が本質的なものであるかどうか济検討した。紙面の関係 もあり，主としてそれらの諸結果を報告する。 


\section{§2. 組分けの基復}

Table I.

地球物理第 I 巻2) 所揭の別府地方（所謂速見火山地区）を中心に， 1929年から1935年に亘って観測された資料の中，三成分の判然とし たもの66個を任意抽出し，之を記録された最大振幅について，その 最小值から最大值の間を種々の階級(等間隔の)に組分けし，夫ょの 場合を最小自乗法によって求めた結果は第 I 表に示す如くである.

因に統計において階級数決定に用いる Sturges の公式 ${ }^{3)}$ に低れ ば, 大いさ $N$ の資料を整理する時の適当な階級数 $n$ は

\begin{tabular}{c|c}
$\begin{array}{c}\text { class } \\
\text { number }\end{array}$ & The $m$ value \\
\hline 5 & $1 .{\varepsilon 0_{362}}$ \\
7 & $1.68_{158}$ \\
\hline 9 & $1.45_{586}$ \\
\hline 11 & $1.30_{868}$ \\
17 & $1.04_{317}$ \\
\hline 21 & $0.89_{888}$
\end{tabular}

$$
n=1+\log N / \log 2
$$

と与えられる. $N=66$ に対しては $n=7$ 階級が適当である（基準 II）. 階級巾の別の基準とし ては夫љ階級巾 $w \leq \frac{1}{3} \sigma^{4}$ )による場合（基準 III)，巾 $w \leq \frac{1}{4} \sigma^{5}$ )による場合 (基準 IV)，を汳 に用いた（但し $\sigma$ は母標準偏差，なお基準 I は階級数の少い場合として便宜に例えばこの 場合 5 階級とした).

\section{§ 3. 基华別方向別の考察}

これら諸基準に基いて速見地区の微弱小地震に関し，方向別等に算出した指数の值は第I表 に示す。

Table II.

\begin{tabular}{|c|c|c|c|c|c|}
\hline \multirow[b]{2}{*}{ Basis } & \multicolumn{4}{|c|}{ Class number } & \multirow[b]{2}{*}{$\begin{array}{c}\text { N. \& } S \\
\text { Vib. }\end{array}$} \\
\hline & $\mathbf{N}_{\text {Vib. }}^{\&} \mathrm{~S}$ & $\begin{array}{l}\text { E. \& V } \\
\text { Vib. }\end{array}$ & $\underset{\text { Vib. }}{\text { U. I }}$ & $\begin{array}{c}\text { Result. } \\
\text { Vib. }\end{array}$ & \\
\hline $\begin{array}{l}\text { I } \\
\text { II } \\
\text { III } \\
\text { IV }\end{array}$ & $\begin{array}{r}5 \\
7 \\
17 \\
21\end{array}$ & $\begin{array}{r}5 \\
7 \\
18 \\
24\end{array}$ & $\begin{array}{r}5 \\
7 \\
11 \\
19\end{array}$ & $\begin{array}{r}5 \\
7 \\
14 \\
19\end{array}$ & $\begin{array}{l}1 . \varepsilon 0_{36} \\
1.68_{15} \\
1.04 \\
0.89_{88}\end{array}$ \\
\hline
\end{tabular}

The values of $m$

\begin{tabular}{c|c|c}
$\begin{array}{c}\text { E. \& W. } \\
\text { Vib. }\end{array}$ & $\begin{array}{c}\text { U. \& D. } \\
\text { Vib. }\end{array}$ & $\begin{array}{c}\text { Resultant } \\
\text { Vib. }\end{array}$ \\
\hline $1.82_{262}$ & $1.70_{821}$ & $1.63_{841}$ \\
$1.59_{002}$ & $1.38_{389}$ & $1.59_{889}$ \\
$1.12_{860}$ & $1.24_{890}$ & $1.13_{519}$ \\
$0.99_{526}$ & $1.14_{657}$ & $1.11_{566}$
\end{tabular}

Table III.

\begin{tabular}{|c|c|c|c|c|c|c|}
\hline Basis & Factor & Variation & D. F. & $\begin{array}{l}\text { Unbiased } \\
\text { variance }\end{array}$ & Snedecor's F & Significant \\
\hline I & $\begin{array}{l}\text { Within A } \\
\text { groups } \\
\text { Residual B } \\
\text { Sum C } \\
\end{array}$ & $\begin{array}{l}0.99293 \\
0.01051 \\
1.00344\end{array}$ & $\begin{array}{r}11 \\
3 \\
14\end{array}$ & $\begin{array}{l}0.090264 \\
0.003503_{3}\end{array}$ & 25. $77 \underset{<}{<} \quad 27.13$ & $*$ \\
\hline II & $\begin{array}{l}\mathrm{A} \\
\mathrm{B} \\
\mathrm{C}\end{array}$ & $\begin{array}{l}0.73507 \\
0.03271 \\
0.76778\end{array}$ & $\begin{array}{r}15 \\
3 \\
18\end{array}$ & $\begin{array}{l}0.049005 \\
0.010903\end{array}$ & 4. $50<8.70,26.87$ & not \\
\hline 血 & $\begin{array}{l}\text { A } \\
\mathbf{B} \\
\mathbf{C}\end{array}$ & $\begin{array}{l}1.39629 \\
0.02648 \\
1.42277\end{array}$ & $\begin{array}{r}31 \\
\tilde{3} \\
34\end{array}$ & $\begin{array}{l}0.045042 \\
0.00882 \epsilon_{7}\end{array}$ & 5. $10<8.62,26.49$ & " \\
\hline $\mathbf{N}$ & $\begin{array}{l}\mathrm{A} \\
\mathbf{C}\end{array}$ & $\begin{array}{l}2.28349 \\
0.07012 \\
2.35361\end{array}$ & $\begin{array}{r}42 \\
3 \\
45\end{array}$ & $\begin{array}{l}0.054369 \\
0.023373\end{array}$ & $2.33<8.60,26.40$ & " \\
\hline
\end{tabular}


こして，てれら指数值の相違が果して本質的なものであるかどうかは相関分析法によって袷 定することが出米る（第 III 表）。

これに依れば，基準Iの場合以外は何れも方问別等によって，危険率 $5 \%$ ，1\%以下で母集 沂における指数 $m$ の优（母回帰保数 $\beta$ ）の一様性流却されないといえる.

Table IV.

\begin{tabular}{|c|c|c|c|c|c|c|}
\hline Direction & Factor & Variation & D. F. & $\begin{array}{l}\text { Unbiased } \\
\text { variance }\end{array}$ & Snedecor's $F \quad F_{05}, F_{01}$ & Significant \\
\hline $\begin{array}{l}\text { N. \& S. } \\
\text { Vib. }\end{array}$ & $\begin{array}{l}\mathrm{A} \\
\mathrm{B} \\
\mathrm{C}\end{array}$ & $\begin{array}{l}1.43229 \\
0.58528 \\
2.01757\end{array}$ & $\begin{array}{r}26 \\
3 \\
29\end{array}$ & $\begin{array}{l}0.055088 \\
0.19509\end{array}$ & $3.54>2.9844 .64$ & * \\
\hline $\begin{array}{c}\text { E. \& W. } \\
\text { Viv. }\end{array}$ & $\begin{array}{l}\mathrm{A} \\
\mathrm{B} \\
\mathrm{C}\end{array}$ & $\begin{array}{l}0.88404 \\
0.36347 \\
1.24751\end{array}$ & $\begin{array}{r}25 \\
3 \\
28\end{array}$ & $\begin{array}{l}0.035362 \\
0.12116\end{array}$ & $3.43>2.99$ & * \\
\hline $\begin{array}{l}\text { U. \& D. } \\
\text { Vib. }\end{array}$ & $\begin{array}{l}\mathrm{A} \\
\mathrm{B} \\
\mathrm{C}\end{array}$ & $\begin{array}{l}1.75621 \\
0.11953 \\
1.87574\end{array}$ & $\begin{array}{r}24 \\
3 \\
27\end{array}$ & $\begin{array}{l}0.073175 \\
0.039843\end{array}$ & $1.84<8.64,26.60$ & not \\
\hline $\begin{array}{l}\text { Result. } \\
\text { Vib. }\end{array}$ & $\begin{array}{l}\mathrm{A} \\
\mathrm{B} \\
\mathrm{C}\end{array}$ & $\begin{array}{l}1.33524 \\
0.18908 \\
1.522 € 0\end{array}$ & $\begin{array}{r}24 \\
3 \\
27\end{array}$ & $\begin{array}{l}0.055635 \\
0.063027\end{array}$ & 1. $13<3.01,4.72$ & " \\
\hline
\end{tabular}

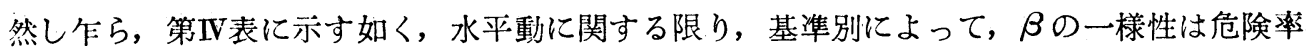
$5 \%$ 以下で否定される. 従って水平動を取扱う場合, 基準即ち階級数を指定することが必要と なる。

Table V.

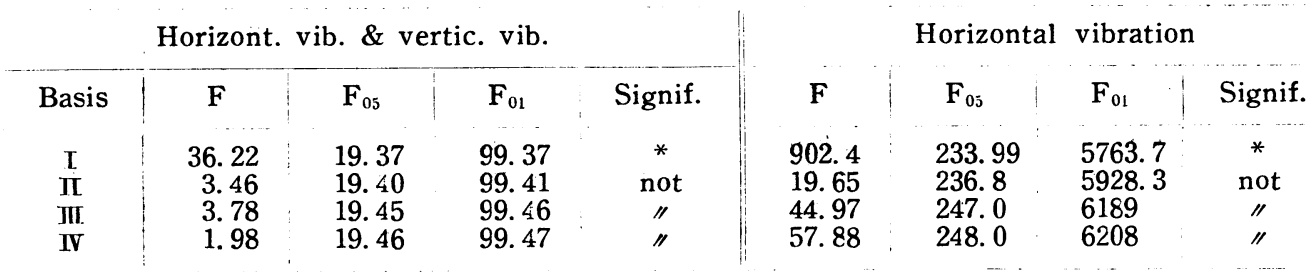

なお第 $\mathrm{V}$ 表の結果から，基準 $\mathrm{I}$ 以外の組分けの場合には水平動に関しては，東西動，南北動 何れを採用するも $\beta$ の一様性は否定されないてとが分る（危険率 $5 \%$ 以下）.

\section{§4. $\beta=1.9$ の模定}

問題の指数 $\boldsymbol{m}$ が主たる統計的意味を有するのは微弱小地震に関し成立する石本飯田の統計 式から，Gutenberg と Richter が導いたエネルギーとその頻度の関係式6) を，誘導し得る7) 点に在り, その数值的根拠は $m=1.9$ と置く所に在る. 今 $\beta=1.9$ を検定して見よう, その絬 果は第 VI 表の如く，基準 II による階級数の場合，水平動に関しては，母集団における指数値 $\beta=1.9$ は危険率 $5 \% ， 1 \%$ 以下で裹却されないこととなる。 
Table VI.

\begin{tabular}{|c|c|c|c|c|c|c|}
\hline Direction & Basis & $m$ & $\begin{array}{c}S_{m} \\
\text { (Stand. Dev. } \\
\text { of } m \text { ) }\end{array}$ & $\frac{m-1.9}{S_{m}}$ & $t_{01}$ & Significant \\
\hline N. \& S. Vib. & $\stackrel{\text { I }}{\text { II }}$ & $\begin{array}{l}1.80_{3} \\
1.68_{1}\end{array}$ & $\begin{array}{l}0.451 \\
0.228\end{array}$ & $\begin{array}{l}0.215<3.182, \\
0.961<4.303,\end{array}$ & $\begin{array}{l}5.841 \\
9.925\end{array}$ & $\begin{array}{c}\text { not } \\
" 1\end{array}$ \\
\hline $\begin{array}{l}\text { E. \& W. } \\
\text { Vib. }\end{array}$ & $\begin{array}{l}\text { I } \\
\text { II } \\
\text { III } \\
\text { IV }\end{array}$ & $\begin{array}{l}1.82_{2} \\
1.59_{0} \\
1.12_{9} \\
0.99_{1}\end{array}$ & $\begin{array}{l}0.315 \\
0.213 \\
0.285 \\
0.217\end{array}$ & $\begin{array}{c}0.248<2.776, \\
1.455<3.183, \\
2.705<2.776, \\
4.189>2.776 \\
<\end{array}$ & $\begin{array}{l}4.604 \\
5.841 \\
4.604 \\
\\
4.604\end{array}$ & $\begin{array}{c}\text { not } \\
\text { "I } \\
\text { (barely) } \\
*\end{array}$ \\
\hline
\end{tabular}

以上を要約するならば，石本一飯田の統計式において，最大振幅指数 $m$ を問題とする時， 水平動の場合には, 南北動又は東西動の何れかを取扱えばよく, 而も $\beta=1.9$ は否定されない のである．従って計算の便宜上，又主たる統計的意味からも，最大振幅に対する組分けの一基 準として，筆者は Sturges の公式によって階級数を決定した後，指数の值を論じることとし た.

\section{§5. 阿武山における锶測結果}

1949 年始めから 1953 年末に亘る阿武山地震観測所の資料（固有周期 8 秒, 倍率 2000 倍 の Galitzin 型南北動地震計に依る）に基いて指数 $\boldsymbol{m}$ を上述の方式に従って規模別, 領域別, 年度別に求めた結果を次に記す.但し阿武山を中心とし P-S 1 分以内の地震群を採択した.

Table VII (A).

\begin{tabular}{c} 
Richter's Scale \\
$M$ \\
\hline $0 \sim 3$ \\
$0 \sim 4$ \\
$0 \sim 5$ \\
$0 \sim 6$
\end{tabular}

$$
\begin{aligned}
& \text { The } m \text { value } \\
& \text { (in 1949) }
\end{aligned}
$$

$$
\begin{aligned}
& 1.87_{228} \\
& 2.39_{962} \\
& 1.91_{823} \\
& 2.09_{771}
\end{aligned}
$$

Total frequency

$$
\begin{array}{r}
275 \\
908 \\
1080
\end{array}
$$$$
1306
$$

class number

\begin{tabular}{l}
$n$ \\
\hline 9 \\
10 \\
11
\end{tabular}

Table VII (B).

\begin{tabular}{l|l}
$M$ & $m$ \\
\hline $0 \sim 3$ & $1.87_{228}$ \\
$0 \sim 4$ & $2.39_{962}$ \\
$0 \sim 5$ & $1.99_{823}$ \\
$0 \sim 6$ & $2.09_{771}$
\end{tabular}

$S_{m}$

$0.04<9$

0.251

0.355

0.204
D. F.

8

9

10

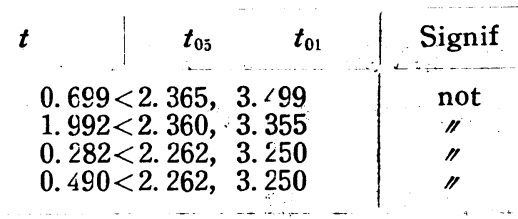

Table VII (C).

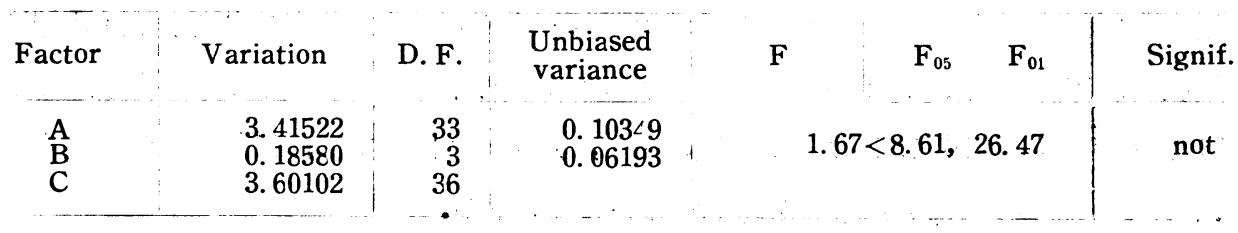


Table VIII (A).

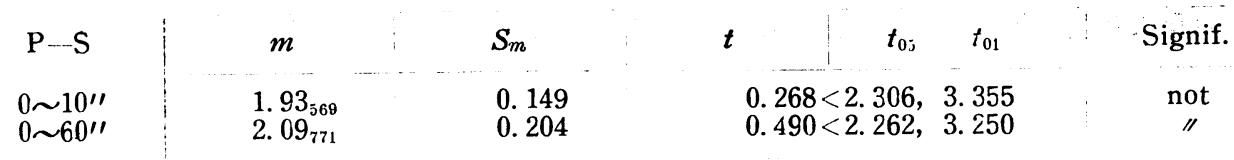

Table VIII (B).

\begin{tabular}{|c|c|c|c|c|c|}
\hline Factor & Variation & D. F. & $\begin{array}{l}\text { Unbiased } \\
\text { variance }\end{array}$ & $F_{05} \quad F_{0}$ & Signif \\
\hline $\begin{array}{l}\mathrm{A} \\
\mathrm{B} \\
\mathrm{C}\end{array}$ & $\begin{array}{l}0.76879 \\
0.01761 \\
0.78640\end{array}$ & $\begin{array}{r}17 \\
1 \\
18\end{array}$ & $\begin{array}{l}0.05223 \\
0.01761\end{array}$ & $2.57<246, \quad 6 \check{c} 08$ & not \\
\hline
\end{tabular}

Table IX (A).

\begin{tabular}{|c|c|c|c|c|c|c|c|c|c|}
\hline Year & $N$ & $n$ & $m$ & $t$ & $t_{05}$ & $t_{01}$ & $\begin{array}{c}5 \% \\
\text { Signif. }\end{array}$ & $\begin{array}{c}1 \% \\
\text { Signif. }\end{array}$ & $\begin{array}{c}1 \% \\
\beta=1.9\end{array}$ \\
\hline $194 \leftrightarrows$ & 1306 & 11 & 2.09 & 0.490 & 2. 262 & 3. 250 & not & not & is no \\
\hline 1950 & 1273 & 11 & 2.13 & 0.891 & 2. & 3. 250 & "I & "I & rejected \\
\hline 1951 & 1860 & 12 & 2. $25_{717}$ & 2. 156 & 2. 2 & 3. 169 & "I & "I & "I \\
\hline 195 & 1484 & 12 & 2. $09_{450}$ & 2. 378 & 2. 228 & 3. 169 & $*$ & " & "I \\
\hline 1953 & 2079 & 12 & $1.99_{037}$ & 0.783 & 2. 228 & 3. 169 & not & "I & " \\
\hline
\end{tabular}

Table IX (B).

\begin{tabular}{l|rrrrrrr} 
Factor & Variation & D. F. & $\begin{array}{c}\text { Unbiased } \\
\text { variance }\end{array}$ & F & $F_{05}$ & $F_{01}$ & Signif. \\
\cline { 1 - 2 } A & 2.02899 & 47 & 0.043170 & & $2.94<5.71,13.71$ & not \\
B & 0.05883 & 4 & 0.014708 & & &
\end{tabular}

以上の結果から

i）各規模別によっては母集団における指数値 1.9 を否定することは出来ないし（第 VII 表 (A)，(B))，その一様性さえ否定することは出来ない（第VII表 (C)).（危険率夫ァ $5 \% ， 1 \%$ 以下).

ii） 又観測する震源群領域の広狭によっても，i）と闰様のととがいわれる(第听表 (A) (B)). 従って最初設けられた様な微弱小地震についてという但書は必要でなく, 要するに有限領域 以の地震群について考慮されればよい.

iii）更に 1949 年 1 月始めから 1953 年 12 月末までの 5 ケ年の資料につき, 各年度每に ついて検定した結果も全く同様であって， $\beta=1.9$ 並にその一様性は否定出来ないこととなっ た (伦険率 $1 \%$ 以下). 唯 1952 年について忠, 危険率 $5 \%$ で $\beta=1.9$ が否定されるけれど も, これは 3 月中们頃の大聖寺沖地震以後地震計の感度が急激に低下したため, その忦復侍ま での（3 月中们〜6 月末）資料を欠くためと思われる。 
終りに本研究に際し, 終始御想篤なる御指導を賜った恩師佐々憲三教授に厚く感謝致します。 なお貴重な資料を提供下さった阿武山地震観測所の北村俊吉氏の御厚意を深謝します。

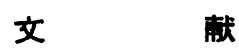

(1) M. Ishimoto and K. Iida; Bull. Earthq. Res. Inst., 17 (1939).

(2) Gẹophysical Inst., Kyoto Universty: Geophysics, 1 (1937).

(3) H. A. Sturges; Journal of the American Statistical Association, 21 (1926).

(4) G. Taguchi; Quality Control, 2, No. 9, (1951).

(5) R. A. Fisher; Statistical Methods for Research Workers, (1950).

(6) B. Gutenberg and C. F. Richter; Seismicity of the Earth, (1949).

(7) T. Asada, Z. Suzuki and Y. Tomoda; Bull. Earthq. Res. Inst., 29 (1951). 